\title{
La educación en la sociedad del conocimiento
}

\author{
M.Sc. Karen María Acevedo Mena \\ Máster en Psicología Clínica y de la Salud \\ UNAN-MANAGUA \\ https://orcid.org/0000-0002-3449-2600 \\ karenacevedomena@hotmail.com \\ M.Sc. Skarlet Romero Espinoza \\ Máster en Metodología y Didáctica para la Educación Superior \\ UNAN-MANAGUA \\ https://orcid.org/0000-0003-1027-0234 \\ skarlet.romero.espinoza@hotmail.com
}

Fecha de recepción: 25 de octubre, 2019 / Fecha de aceptación: 14 de noviembre, 2019

https://doi.org/10.5377/torreon.v8i22.9032

Palabras clave: educación, educando, docente, sociedad del conocimiento

\section{RESUMEN}

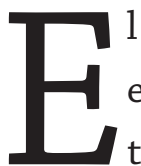

1 presente escrito es un ensayo de reflexión sobre qué papel debe jugar la educación en la sociedad del conocimiento. Este concepto que se refiere a los cambios y transformaciones sociales que se están produciendo en la sociedad actual e implica que analicemos si estamos educando a los individuos para que se adapten a estos cambios de tal forma que podamos realizar los ajustes necesarios en los sistemas educativos de todos los niveles, en especial en la Educación Superior. Para ello, en el desarrollo de este escrito se indaga en las demandas que se exige a la educación en esta nueva sociedad, pero principlamente se reflexiona sobre nuestro rol como docentes el cual debe ser de facilitador que guía al educando en el proceso de enseñanza-aprendizaje y en especial que forma individuos para la vida en las dimensiones: profesional, social y personal. Por último, se consideran las limitaciones que existen en la sociedad del conocimiento las cuales impiden la inclusión de todos los miembros de la sociedad. 


\section{INTRODUCCIÓN}

El presente ensayo se basa en una reflexión sobre cómo debe ser concebida la educación en la sociedad del conocimiento. Esta reflexión parte de la urgencia de reconocer que la sociedad actual atraviesa un sin número de cambios y transformaciones que obligan a los sistemas educativos y educadores de todo el mundo a preguntarnos: ¿cómo estamos educando? ¿Estamos formando futuros profesionales competentes para enfrentarse a la sociedad actual? Estas interrogantes nos llevan a replantear la concepción que teníamos de la educación para dar lugar a nuevas formas de comprenderla dentro de la sociedad del conocimiento. Para ello, primeramente debemos tomar conciencia de que la educación es el eje principal de la trasformación de una sociedad.

Paur, Rosanigo y Bramati (2006) reafirman que actualmente aparece una nueva sociedad que es dinámica, intercomunicada, global, que cambia rápidamente al ritmo de los avances científicos y del nuevo contexto socioeconómico mundial. Estos cambios afectan profundamente todos los ámbitos de la actividad económica, cultural y social de cada país y son tan intensos que se pueden considerar que nos están conduciendo a una nueva era a la que podemos llamar sociedad del conocimiento.

La definición de estos autores acentúa los cambios que se producen por los grandes y rápidos avances de la sociedad actual.

Por otra parte, Krüger (2006) refiere que la sociedad del conocimiento "se trata de un concepto que aparentemente resume las transformaciones sociales que se están produciendo en la sociedad moderna y sirve para el análisis de estas trasformaciones” (p.1). Este concepto coincide con lo planteado por Díaz (2011) quien también define la sociedad del conocimiento como "un término que sintetiza las trasformaciones sociales que se producen en la actualidad y que sirve para el análisis de estos cambios" (p.390). Ambos conceptos destacan la trasformación social que se produce en una sociedad del conocimiento.

\section{La Educación en la Sociedad del conocimiento}

Una vez expuestas las definiciones de la sociedad del conocimiento, ahora nos concierne explicar qué papel debe jugar la educación en ésta. Desde la perspectiva de la Organización de las Naciones Unidas para la Educación, la Ciencia y la Cultura [UNESCO] (2005) citada por Forero (2009), el acceso a la educación, información y la libertad de expresión son los pilares de la sociedad del conocimiento. El concepto de sociedad del conocimiento es importante no sólo para el crecimiento económico de un país sino también para desarrollar todos los sectores de la sociedad desde el punto de vista humano. Por lo tanto, es en este aspecto que la educación debe fundamentalmente centrarse, es decir, debemos educar para formar individuos con calidad humana que aporten al desarrollo económico, político y social desde sus profesiones. 
En la sociedad actual, el conocimiento se ha convertido en un elemento fundamental de la vida humana, ya que todas las actividades económicas, laborales, educativas, culturales y comunicativas requieren de competencias cognitivas y mentales (Forero, 2009). Por ende, los sistemas educativos en todos los niveles deben cambiar los paradigmas tradicionales que han venido aplicando para dar lugar a paradigmas más pertinentes en una sociedad y en un mundo tan cambiante y demandante.

Paur, Rosanigo y Bramati (2006) refuerzan este planteamiento al referir que se debe pasar de un sistema tradicional que tiene al profesor como actor principal, como dueño de los conocimientos que transfiere al educando, el cual es un actor pasivo, receptor de la información a un sistema que:

Da lugar a nuevas metodologías y nuevos roles docentes, más centrados en el diseño y gestión de actividades y entornos de aprendizaje, en la investigación sobre la práctica, selección de contenido Profesor-Estudiante, recursos, en la orientación, asesoramiento y dinámica de grupos, en la evaluación formativa y en la motivación de los estudiantes (p. 465).

En este sentido el profesor adquiere un rol de facilitador que guía al educando en el proceso de enseñanza-aprendizaje, donde diseña actividades dirigidas a la construcción de conocimientos y su aplicación práctica. El educando toma un papel activo, que no debe memorizar información sino analizarla y procesarla de manera que le permita construir el conocimiento y lograr un aprendizaje significativo.

En este nuevo paradigma de la educación se deben promover los procesos de innovación ya que la UNESCO (2005) citada por Forero (2009) establece que el elemento central de las sociedades del conocimiento es la "capacidad para identificar, producir, tratar, transformar, difundir y utilizar la información con vistas a crear y aplicar los conocimientos necesarios para el desarrollo humano" (p. 43).

Además de lo mencionado anteriormente, la educación en la sociedad del conocimiento debe tener claro que el uso del Internet ha generado que se tenga acceso a una cantidad ilimitada de información, por lo que los docentes debemos desarrollar en los educandos habilidades de búsqueda, selección, análisis y síntesis de ese cúmulo de información que tiene disponible. En otras palabras que aprendan a aprender.

Moreno y Velásquez (2012), mencionan que no solo debemos centrarnos en obtener la información, hay que saber buscarla y utilizarla para un bien común, con sentido crítico y un fin utilitario. Lo que indica, que el educando de aprender a utilizar la información y el conocimiento para innovar o solucionar una problemática o necesidad de tal manera que le permita cambiar el mundo que lo rodea, mejorar su calidad de vida, el de su familia y el de su comunidad. Solo de esta manera podemos referir que existe una sociedad del conocimiento. 


\section{Limitantes}

Ahora es importante analizar si los cambios que se deben producir en la educación en las sociedades del conocimiento están al alcance de todos los sistemas educativos y al alcance de todos los actores principales como son los educandos y educadores. En otras palabras, si la sociedad del conocimiento permite la inclusión de todos sus miembros o existen exclusiones; como bien lo señala la UNESCO (2005) citada por Forero (2009) uno de los grandes obstáculos que existen para cumplir con los Objetivos de Desarrollo para el Milenio es la considerable inversión en educación y formación que se requiere para la construcción de una sociedad del conocimiento, además existe una limitante incapacidad para dominar la tecnología y ocurre un fenómeno que es la costumbre que se tiene en las sociedades de guardar el conocimiento, de modo que no se comparte libremente para que todos alcancemos el máximo desarrollo. Esto ocurre porque muchas veces en el ser humano está arraigado el individualismo, el egoísmo y la mala competitividad lo que genera que tengamos estas actitudes.

Tedesco (2003), por su parte nos habla de la sociedad del conocimiento a la que denomina también nuevo capitalismo en el que se pretende incluir en su proceso solo a los individuos que desarrollen las capacidades básicas vinculadas con la educabilidad y empleabilidad con lo cual se excluye el resto de la población que no tenga las características que este nuevo sistema requiere marginando o dejando el resto en su mismo nivel de pobreza, ignorancia y violencia.

Además, Moreno y Velásquez (2012), consideran que los educandos que viven en zonas urbanas se ven privilegiados con las nuevas tecnologías y se excluye a los que viven en zonas rurales y marginales que no tienen acceso a los recursos de infraestructura tecnológica.

Cabe señalar que en Nicaragua las políticas de Gobierno radican en que toda persona tenga acceso a la tecnología, sin embargo, aún tenemos limitaciones, en especial en las zonas rurales del país lo que constituye una exclusión de este sector de la población a la sociedad del conocimiento.

\section{CONCLUSIONES}

La sociedad del conocimiento es un término que se refiere a los cambios y transformaciones sociales que se están produciendo en la sociedad actual. Este concepto nos lleva a replantearnos si estamos educando a individuos para que se adapten a estos cambios. Es decir, si la educación está aportando a las demandas que exige la sociedad del conocimiento.

Uno de los aspectos fundamentales que los sistemas educativos y educadores debemos tomar en cuenta es que nos corresponde formar individuos con altas competencias profesionales pero a la vez con alta calidad humana, solo de esta manera aseguraremos que la sociedad del conocimiento genere desarrollo en todos los sectores de la sociedad y que aporte al bien común. 
Por último, en todos los países del mundo debe promoversela equidad, todos los individuos deben tener derecho a la educación, al acceso al internet, esto para garantizar que exista una verdadera inclusión de todos en la sociedad del conocimiento. Por consiguiente, los docentes tenemos el compromiso social de preparar a los educandos a desarrollar las competencias y capacidades que le permitan resolver los retos del futuro.

\section{LISTA DE REFERENCIAS}

Díaz, V. (2011). Relación entre sociedad del conocimiento, metodología de la investigación científica y producción científica estudiantil en estudiantes de medicina, Chile. Colombia Médica, 42 (3), 388-399. Recuperado de http:// bibliotecadigital.univalle.edu.co:8080/ bitstream/10893/3113/1/relacion.pdf

Forero, I. (2009). La sociedad del conocimiento. Revista Científica General José María Córdova, 5 (7), 40-44. Recuperado de https://www.redalyc.org/ pdf/4762/476248849007.pdf

Krüger, K. (2006). El concepto de sociedad del conocimiento. Geo Crítica, XI (683). Recuperado de http://www.ub.edu/ geocrit/b3w-683.htm
Moreno, H. y Velásquez, R. (2012). La sociedad del conocimiento: inclusión o exclusión. Revista Educación, 36 (2), 1-24. Recuperado de http://www.redalyc.org/ pdf/440/44024857006.pdf

Paur, A., Rosanigo, Z. y Bramati, P. (2006). La educación en la sociedad del conocimiento. Facultad de Ingeniería, UNPSJB. Recuperado de http:// sedici.unlp.edu.ar/bitstream / handle/10915/19258/Documento_ completo.pdf?sequence $=1$ \&isAllowed $=\mathrm{y}$

Tedesco, J. (2003). Investigación educativa: de la ciencia social a la filosofía social. Revista Electrónica de Investigación Educativa, 5 (2). Recuperado de https:// redie.uabc.mx/redie/article/view/86 